\title{
Conversion of fatty acids into hydrocarbon fuels based on a sodium carboxylate intermediate
}

\author{
Deise Morone Perígolo ${ }^{a, d}$, Fabiano Gomes Ferreira de Paula ${ }^{a}$, \\ Marcelo Gonçalves Rosmaninho ${ }^{\mathrm{b}}$, Patterson Patrício de Souza ${ }^{\mathrm{c}}$, Rochel Montero Lago ${ }^{\mathrm{a}}$, \\ Maria Helena Araujo ${ }^{\mathrm{a}, *}$ \\ a Departamento de Química, Universidade Federal de Minas Gerais, Belo Horizonte, MG 31270-901, Brazil \\ b Departamento de Química, Universidade Federal de Ouro Preto, Ouro Preto, MG, 35400-000, Brazil \\ ${ }^{c}$ Departamento de Química, Centro Federal de Educação Tecnológica de Minas Gerais, Belo Horizonte, MG, 30421-169, Brazil \\ d Instituto Federal do Mato Grosso, Campus Avançado de Diamantino, Diamantino, MT, 78402-000, Brazil
}

\section{A R T I C L E I N F O}

\section{Article history:}

Received 16 December 2015

Received in revised form 27 April 2016

Accepted 30 April 2016

Available online $\mathrm{xxx}$

\section{Keywords:}

Free fatty acids

Carboxylate

Fuels

Sodium hydroxide

\begin{abstract}
A B S T R A C T
In this work, it was investigated the conversion of fatty acids into hydrocarbon based on the reaction with NaOH followed by a controlled thermal decomposition. FTIR, Raman, UV-vis, XRD, TG-MS, SEM/TEM, CHN GC-MS showed that precursors based on $\mathrm{NaOH}$ /oleic acid (molar ratios 0.7, 1.0, 1.5 and 2.0) decomposed at $550{ }^{\circ} \mathrm{C}$ to produce three fractions, i.e. liquid (5-37 wt\%), gas (52-70 wt\%) and solid (10-31 wt\%). The liquid fraction was composed of a complex mixture containing mainly aromatic compounds. On the other hand, the major gas fraction showed a remarkable selectivity for propane (56-61 wt\%) with some $C_{1}, C_{2}$, $\mathrm{C}_{4}, \mathrm{H}_{2}$ and $\mathrm{CO}_{\mathrm{x}}$. The solid fraction showed the presence of $\mathrm{Na}_{2} \mathrm{CO}_{3}, \mathrm{Na}_{2} \mathrm{O}$ and particles of amorphous and graphene like carbon. Upon treatment at $800^{\circ} \mathrm{C}$ the carbonate decomposes to $\mathrm{CO}_{2}$, oxidizes the carbon and regenerated the $\mathrm{Na}_{2} \mathrm{O}$ which can potentially be used for a new reaction cycle. These results are preliminary discussed in terms of a catalytic effect of the basic sodium oxide to promote cracking, dehydrogenation and $\mathrm{H}$-transfer reactions.
\end{abstract}

(C) 2016 Elsevier B.V. All rights reserved.

\section{Introduction}

The production of fuels from renewable substrates has been intensively investigated in the last decades [1]. The use of vegetable oils to produce biodiesel is currently the most important route [2-4]. The biodiesel production is usually performed using homogeneous ( $\mathrm{Na}$ and $\mathrm{K}$ hydroxide or alkoxide) or heterogeneous basic catalysts for the transesterification [5-7].

A very important common contamination in vegetable oils is free fatty acids (FFA), for instance, palm (Elaeis guineensis), macauba (Acrocomia aculeata), pinhão manso (Jatropha curcas), usually have high FFA contents, e.g. 20-70\% [8]. Soybean used oil which is a very important waste can also have fairly high concentrations of FFA, e.g. 2-10\% [9]. The presence of these FFA in concentrations higher than $2 \%$ completely hinders the basic catalysed biodiesel production due to the alkaline catalysts deactivation, with the formation of soap (fatty acid salts), stable emulsions and complications in the

\footnotetext{
* Corresponding author.

E-mail address: maria.araujo@pq.cnpq.br (M.H. Araujo).
}

purification step $[6,10,11]$. An alternative route to deal with acidic oils consists in esterification in the presence of homogeneous [12] and heterogeneous acidic catalyst [5-7]. In some cases, the vegetable oil is further hydrolyzed to produce FFA and then esterified using acid catalysis [13].

Different approaches to produce fuels from FFA have been described in the literature such as reform to hydrogen [14], catalytic hydrodeoxygenation [15], hydrotreating [16] and catalytic pyrolysis of soaps [17-20].

In this work, it is investigated the conversion of free fatty acids contaminants directly into hydrocarbon fuels. In this process, the fatty acid reacts with $\mathrm{NaOH}$ to form a sodium carboxylate intermediate as shown in Eq. (1).

$\mathrm{C}_{\mathrm{n}} \mathrm{H}_{\mathrm{m}} \mathrm{COOH}+\mathrm{NaOH} \rightarrow \mathrm{C}_{\mathrm{n}} \mathrm{H}_{\mathrm{m}} \mathrm{COO}^{-} \mathrm{Na}^{+}+\mathrm{H}_{2} \mathrm{O}$

The sodium carboxylate can then be thermally treated to decompose due to the strong $\mathrm{R}-\mathrm{COO}-\mathrm{Na}+$ ionic interaction the sodium cation can retain the oxide anion, and a deoxygenation might take place. The deoxygenation process of the carboxylate can lead to the 
fragmentation of the FFA molecule producing hydrocarbon derivatives and likely carbon oxides and sodium oxide (Eq. (2)).

$\mathrm{C}_{\mathrm{n}} \mathrm{H}_{\mathrm{m}} \mathrm{COO}^{-} \mathrm{Na}^{+} \rightarrow$ hydrocarbons $+\mathrm{CO}_{\mathrm{x}}+\mathrm{Na}_{2} \mathrm{O}$

Hereon, a detailed investigation of the processes described in Eqs. (1) and (2) using oleic acid $\left(\mathrm{CH}_{3}\left(\mathrm{CH}_{2}\right)_{7} \mathrm{CH}=\mathrm{CH}\left(\mathrm{CH}_{2}\right)_{7} \mathrm{COOH}\right)$ and $\mathrm{NaOH}$ with different molar ratios followed by thermal decomposition is described with the characterization of the different solid, liquid and gas products.

\section{Experimental}

The precursors were synthetized from the reaction of $\mathrm{NaOH}$ and oleic acid $(\mathrm{OA})$ in different molar ratios $(0.7,1.0,1.5$ and 2.0). The resultant mixture was treated at $80^{\circ} \mathrm{C}$ for $24 \mathrm{~h}$ and then cooled in a desiccator. The carboxylate salts were characterized by Infrared Spectroscopy (IR, Perkin-Elmer Spectrum GX FT-IR System, $4000-400 \mathrm{~cm}^{-1}, 4 \mathrm{~cm}^{-1}$ of resolution, 64 scans, $\mathrm{KBr}$ pellets) and Thermogravimetric Analysis coupled to Mass Espectrometry in an argon flux of $20 \mathrm{~mL} \mathrm{~min}^{-1}$, temperature range of $40-900^{\circ} \mathrm{C}$ and heating rate of $5^{\circ} \mathrm{C} \mathrm{min}^{-1}$ (TG-MS, NETZSCH thermobalance model STA 449 F3 coupled with mass spectrometer NETZSCH Aëolos model QMS 403C with EI and quadrupole analyzer).

For the thermal decomposition experiments, $60-100 \mathrm{mg}$ of the carboxylate salts were placed in a closed tubular quartz reactor (batch mode) connected with a condenser to collect the liquid products and a volumetric system to measure and collect the gas products for GC analysis. The reactor was heated in a ceramic furnace from room temperature to 550 and to $900{ }^{\circ} \mathrm{C}$, both with a heating rate of $10^{\circ} \mathrm{C} \mathrm{min}^{-1}$. The materials were kept at those temperatures for $20 \mathrm{~min}$. From this experiment, three fractions were obtained: solid, liquid and gaseous.

The solid products of the thermal decomposition experiments were collected and characterized by Raman spectroscopy (Bruker Senterra, CCD detector, $633 \mathrm{~nm}$ and $2 \mathrm{~mW}$ LASER), X-Ray Diffraction (XRD, Shimadzu XRD-7000, $\mathrm{Cu}(\mathrm{K} \alpha)$ radiation, scanning range $10-80^{\circ}, 4^{\circ} \mathrm{min}^{-1}$ ), Thermogravimetric Analysis (TG, Shimadzu, model DTG-60H, air or nitrogen flow of $50 \mathrm{~mL} \mathrm{~min}^{-1}$, temperature range of $25-900^{\circ} \mathrm{C}$ and heating rate of $\left.10^{\circ} \mathrm{C} \mathrm{min}^{-1}\right)$, Scanning Electron Microscopy (SEM, Quanta 200 FEI) and Transmission Electron Microscopy (TEM, Tecnai G2-20 - SuperTwin FEI - 200 kV). Moreover, the solution obtained after washing the solid with water was analyzed by Total Organic Carbon Analysis (TOC, Shimadzu model TOC-V CPH, 1000 times dilution factor).

The liquid products condensed in a trap during the thermal decomposition experiment were collected and characterized by Elemental Analysis (CHN, Perkin Elmer), Infrared spectroscopy and Gas Chromatography coupled with mass spectroscopy (GC-MS, Agilent model GC 7890, HP-5 column) coupled with a mass spectrometer model 5975C with EI and a quadrupole analyzer).

The gas products formed during the thermal decomposition experiment were characterized by Gas Chromatography (GC, Shimadzu GC-2014 ATF equipped with methanator, TCD and FID).

\section{Results and discussion}

\subsection{Synthesis and characterization of the precursors}

The precursors were synthetized from the reaction of $\mathrm{NaOH}$ and oleic acid (OA) in different molar ratios $(0.7,1.0,1.5$ and 2.0$)$ named hereon as $0.7 \mathrm{Na}, 1.0 \mathrm{Na}, 1.5 \mathrm{Na}$ and $2.0 \mathrm{Na}$, respectively.

IR spectra of the Na oleate precursors showed that the carbonyl band of the oleic acid at $1710 \mathrm{~cm}^{-1}$ strongly decreased with the appearance of a new band at $1560 \mathrm{~cm}^{-1}$ related to the $\mathrm{Na}^{+}$carboxylate which suggests that most of the oleic acid has been reacted (Fig. 1) [21].

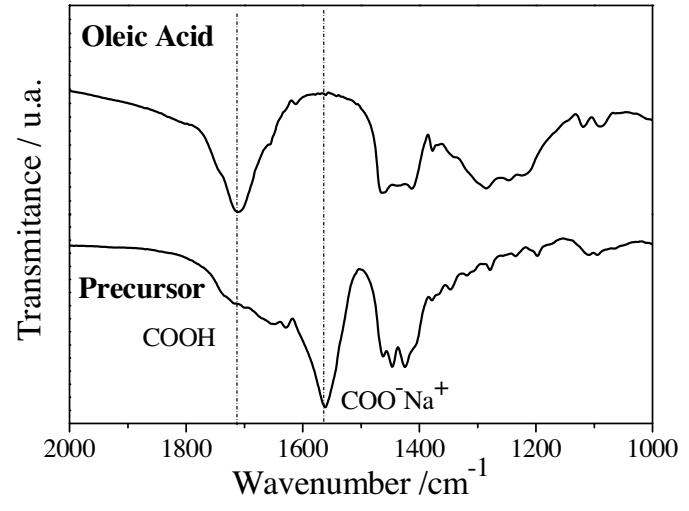

Fig. 1. FT-IR spectra obtained for precursors and oleic acid.

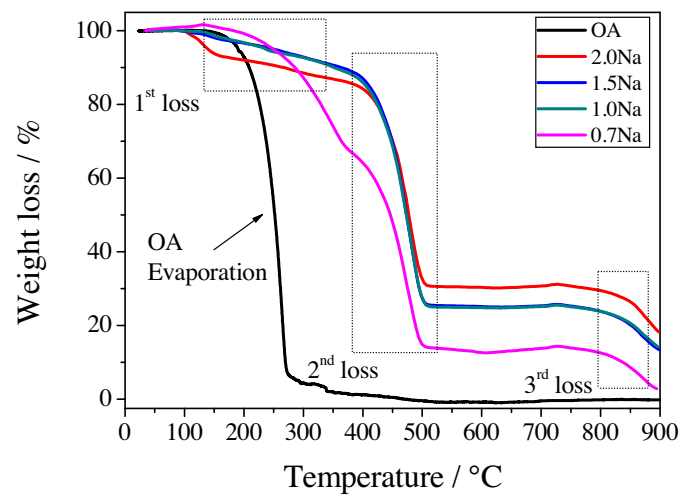

Fig. 2. TG analyses obtained for the precursors and pure oleic acid.

The temperature in which the carboxylates would decompose to produce hydrocarbons was determined by a TG study under argon atmosphere (Fig. 2).

The pure oleic acid presented a single weight loss in the temperature range of $\mathrm{ca} .200-300^{\circ} \mathrm{C}$ due to evaporation. On the other hand, the precursors showed three main weight losses in temperature ranges of $100-400^{\circ} \mathrm{C}, 400-500^{\circ} \mathrm{C}$ and $700-900^{\circ} \mathrm{C}$. The precursor $0.7 \mathrm{Na}$ showed a significant gradual weight loss between 100 and $350^{\circ} \mathrm{C}$, likely related to partial oleic acid evaporation due to its high concentration and low $\mathrm{Na}^{+}$content. On the other hand, for the $2.0 \mathrm{Na}$ precursor a weight loss of $\mathrm{ca} .10 \%\left(100-150^{\circ} \mathrm{C}\right)$ was observed, which is probably related to water molecules due to high $\mathrm{Na}^{+}$content on the sample. This event was followed by a small and gradual weight decrease of $\mathrm{ca} .10 \%$, up to $400^{\circ} \mathrm{C}$. For the precursors $1.0 \mathrm{Na}$, $1.5 \mathrm{Na}$ and $2.0 \mathrm{Na}$, a significant weight loss of $c a$. $60 \%$ was observed between 400 and $500^{\circ} \mathrm{C}$. These exothermic weight losses (see DTA in Supplementary material) are likely related to the decomposition of the precursors.

A third weight loss can be observed at temperatures higher than $700{ }^{\circ} \mathrm{C}$ which can be related to the carbonate decomposition to $\mathrm{CO}_{2}$ and also to a reported [22] reaction of sodium carbonate with carbon (Eq. (3)) [22]. As expected, this weight loss increases with the increase of $\mathrm{Na}^{+}$content in the sample e.g. $3 \%$ for $0.7 \mathrm{Na}$ and $12 \%$ for $2.0 \mathrm{Na}$.

$\mathrm{Na}_{2} \mathrm{CO}_{3(\mathrm{~s})}+2 \mathrm{C}_{(\mathrm{s})} \rightarrow 3 \mathrm{CO}_{(\mathrm{g})}+2 \mathrm{Na}_{(\mathrm{s})}$

\subsection{Investigation of the thermal decomposition of the precursors}

Based on the TG results, the thermal decomposition of the precursors was studied in a tubular reactor in temperatures of 550 and $900^{\circ} \mathrm{C}$. The experiments were carried out under static argon atmosphere and the obtained results at $550^{\circ} \mathrm{C}$ are shown in Fig. 3 . 


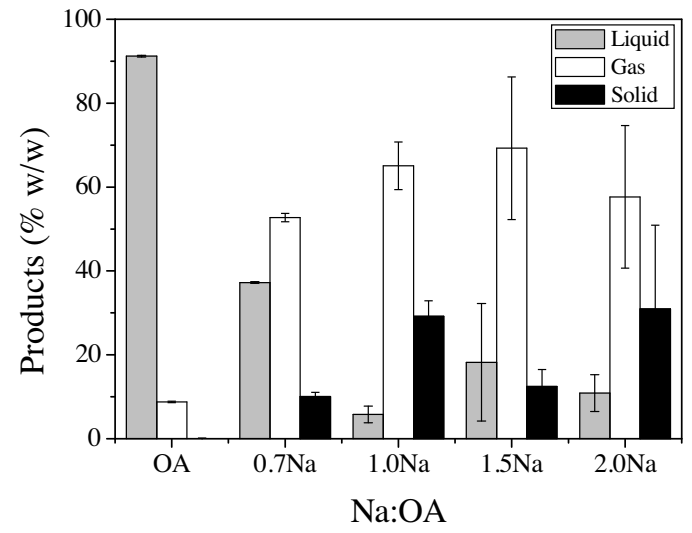

Fig. 3. Product distribution (wt\%) for the thermal decomposition of oleic acid and the different precursors at $550^{\circ} \mathrm{C}$.

Three fractions were obtained: solid, liquid and gas. It can be observed that the pure oleic acid almost completely evaporates (about 90\%) with the formation of very small amount of gas, probably due to some decomposition process. For all the precursors investigated, the gas fraction was the main product, $\mathrm{ca}$. 52-70 wt\%. The liquid fraction was generally small except for the sample $0.7 \mathrm{Na}$ or any lower sodium content, which is probably due to the evaporation of oleic acid. Previous literature works on the pyrolysis of different $\mathrm{Na}$ and $\mathrm{Ca}$ soaps in the presence of catalysts or under extreme conditions (heating rate of $1000^{\circ} \mathrm{Cs}^{-1}$ ) showed mainly the formation of liquid products [17-20].

\subsection{Characterization of the solid fraction}

The composition of the solid fraction was investigated by different techniques such as XRD, Raman spectroscopy, TG, SEM and TEM.

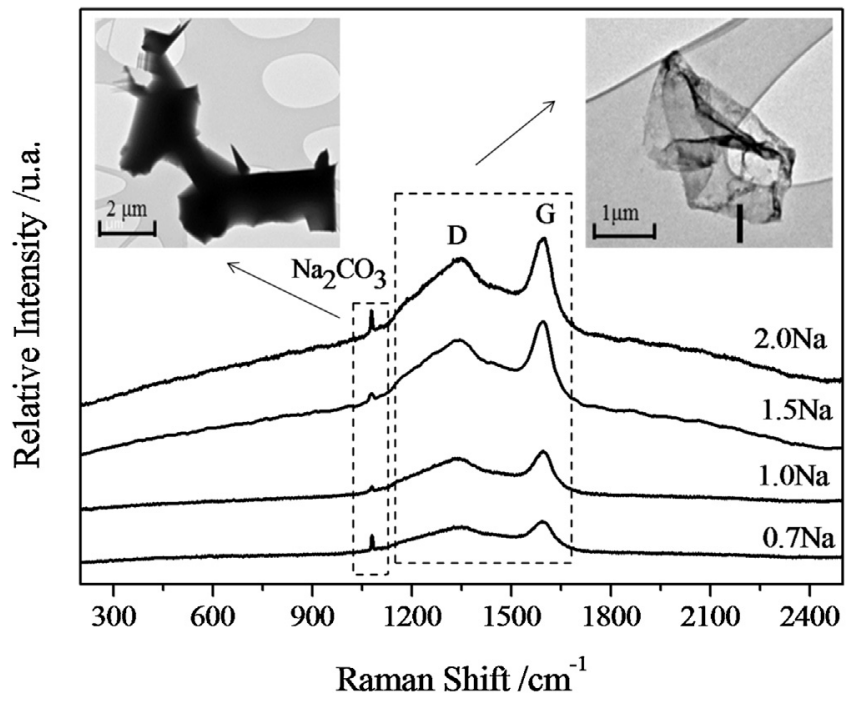

Fig. 4. Raman spectra for the solid obtained by thermal decomposition at $550^{\circ} \mathrm{C}$ of the precursors and selected TEM showing carbon and $\mathrm{Na}_{2} \mathrm{CO}_{3}$ structures.

The XRD patterns obtained for the grey-black solid indicated the presence of sodium carbonate $\left(\mathrm{Na}_{2} \mathrm{CO}_{3}\right.$ JCDPS 37-451, see Supplementary material).

The Raman spectra (Fig. 4) of the solids precursors showed three bands at 1068,1350 and $1588 \mathrm{~cm}^{-1}$. The band at $1068 \mathrm{~cm}^{-1}$ is related to the symmetric stretching of $\mathrm{CO}$ band from $\mathrm{Na}_{2} \mathrm{CO}_{3}$ [23]. TEM images (see detail in Fig. 4) showed many sharp edged dense structures likely related to crystalline $\mathrm{Na}_{2} \mathrm{CO}_{3}$. The bands at 1350 and $1588 \mathrm{~cm}^{-1}$ are referred as D and G bands, respectively, typical for carbonaceous materials [24]. The D band is related to the presence of defective carbon structures whereas the $G$ band is related to $\mathrm{sp}^{2}$ more organized graphene carbon structures [25]. In fact, TEM


Fig. 5. SEM images for the crude solid obtained by thermal decomposition of all precursors at $550^{\circ} \mathrm{C}$.

Please cite this article in press as: D.M. Perígolo, et al., Conversion of fatty acids into hydrocarbon fuels based on a sodium carboxylate intermediate, Catal. Today (2016), http://dx.doi.org/10.1016/j.cattod.2016.04.035 


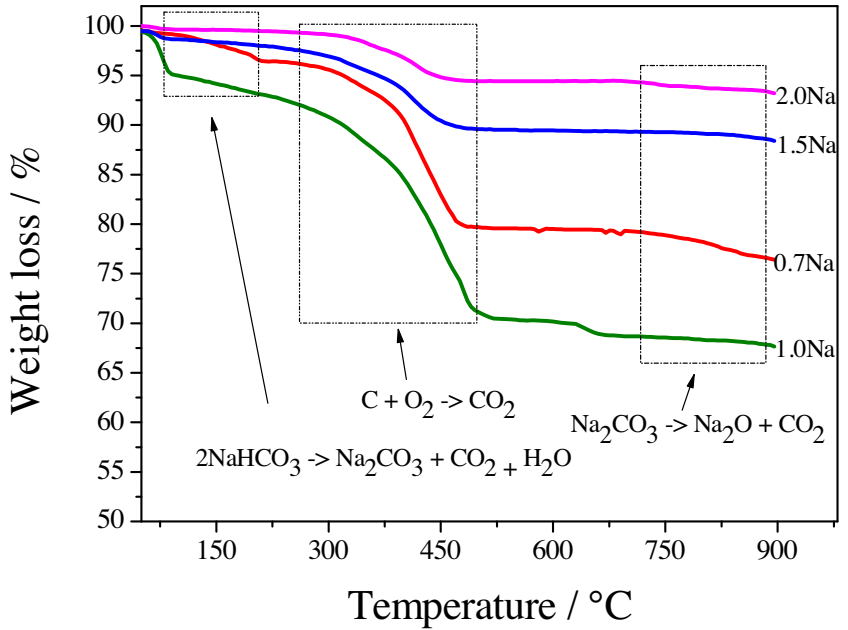

Fig. 6. TG analyses for the solid fraction obtained by thermal decomposition of the precursors at $550^{\circ} \mathrm{C}$

images (see detail in Fig. 4) clearly showed amorphous structures and graphene like particles related to carbon.

After washing the solid with diluted acid, the carbonate band in $1068 \mathrm{~cm}^{-1}$ was removed and only the D and G bands are observed (see Supplementary material). TEM analyses of this washed sample showed the different carbon amorphous and graphene like structures (see Supplementary material).

SEM images (Fig. 5) showed needle-shaped agglomerates structures which are in agreement with $\mathrm{Na}_{2} \mathrm{CO}_{3}$ crystals [26-28].

The amount of carbon present in the solid fraction was determined by the weight loss in the TG (Fig. 6) due to oxidation as shown in Eq. (4).

$\mathrm{C}_{(\mathrm{s})}+\mathrm{O}_{2(\mathrm{~g})} \rightarrow \mathrm{CO}_{2(\mathrm{~g})}$

The carbon oxidation was observed at relatively low temperatures, i.e. $300-500^{\circ} \mathrm{C}$ (Fig. 6) compared to other carbon based materials [29], which suggests a very reactive defective carbon. According to the observed weight losses, the carbon contents were $17,25,9$ and $5 \%$ for the precursors $0.7 \mathrm{Na}, 1.0 \mathrm{Na}, 1.5 \mathrm{Na}, 2.0 \mathrm{Na}$, respectively.

It can also be observed a weight loss at temperatures higher than $750{ }^{\circ} \mathrm{C}$ related to carbonate decomposition [22]. The carbonate content was analyzed by TC after dissolution of the $\mathrm{Na}_{2} \mathrm{CO}_{3}$ in water. Fig. 7 shows the composition of the solid fraction estimated by TG and TC. In all cases, the $\mathrm{Na}_{2} \mathrm{CO}_{3}$ is the main product and the carbon content decreased as excess of sodium is used in the reaction. It is interesting to observe that the $\mathrm{Na}_{2} \mathrm{O}$ does not seem to increase for higher $\mathrm{Na}$ content in the precursor. This is likely related to the catalytic effect of excess sodium on the formation of more solid carbon and also more carbonate.

\subsection{Characterization of the liquid product}

The liquid products were analyzed by $\mathrm{CHN}$ which showed similar results for all samples, i.e. 65-76\% $\mathrm{C}$ and $6-7 \% \mathrm{H}$. This general composition clearly suggests a very high $\mathrm{C} / \mathrm{H}$ ratio which indicates the presence of aromatic compounds. In fact IR spectra (Fig. 8) showed bands in the range of $3040-3290 \mathrm{~cm}^{-1}$ related to $=\mathrm{C}-\mathrm{H}$ stretching, 1400 and $1650 \mathrm{~cm}^{-1}$ possibly due to the $\mathrm{C}=\mathrm{C}$ stretching of aromatic compounds. Some of the spectra showed a small band at $1718 \mathrm{~cm}^{-1}$ indicating the presence of low amounts of carboxylic acids [30]. Moreover, UV-vis spectra (see Supplementary Material) showed bands at $340 \mathrm{~nm}$ related to aromatics.

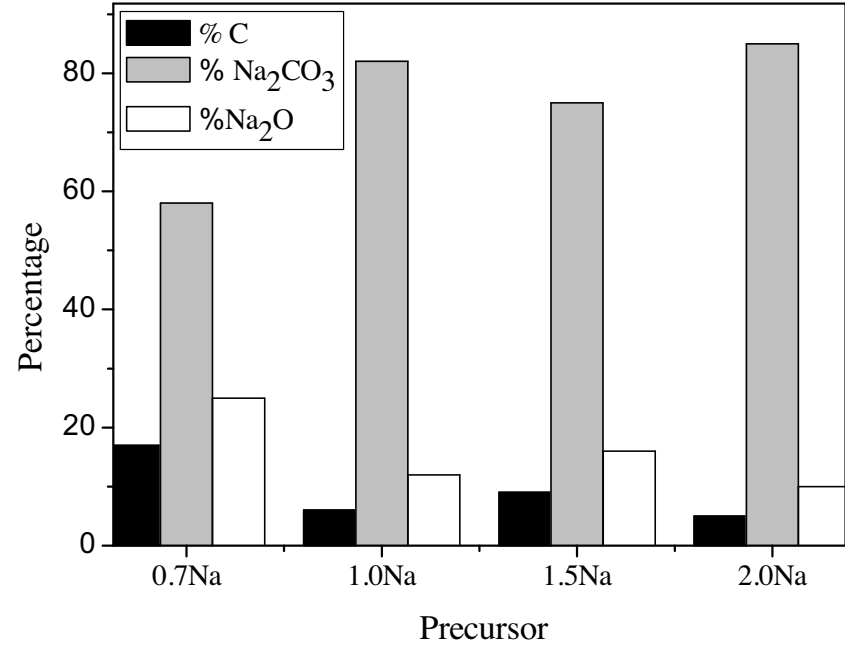

Fig. 7. Composition of the solid fraction.

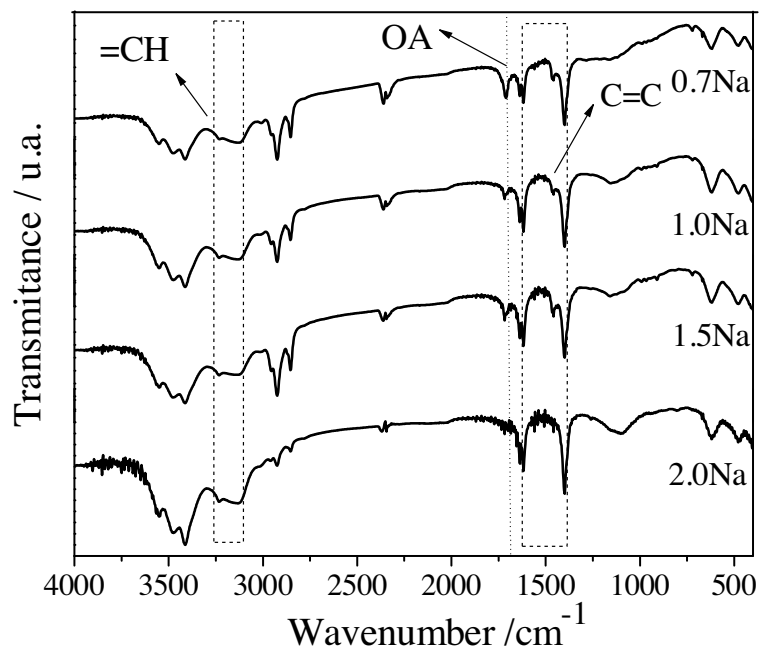

Fig. 8. FT-IR spectra for the liquid fractions obtained by the thermal decomposition of the different precursors.

Preliminary GC-MS showed, besides the presence of oleic acid, the formation of a complex mixture of different hydrocarbons which needs a more detailed characterization.

\subsection{Characterization of the gas fraction}

TG-MS analyses were carried out in order to detect the molecules formed in the gas product during the thermal decomposition. Also, at the end of the experiments, the gases were collected and analyzed by GC. The TGMS obtained results are shown in Fig. 9.

The obtained spectra showed the formation of $\mathrm{H}_{2}, \mathrm{CO}, \mathrm{CO}_{2}$ and hydrocarbons $\mathrm{C}_{1}-\mathrm{C}_{4}$ for all precursors (see the other TGMS profiles in Supplementary material).

The GC analysis showed that, at $550^{\circ} \mathrm{C}$, the gases formed were essentially hydrocarbons (60-70 mol\%), $\mathrm{H}_{2}$ (20-32 mol\%) and carbon oxides (Fig. 10). Moreover, the selectivity for $C_{3}$ was higher than 90 mol\% among the hydrocarbons.

It is interesting to observe that the gas composition were very similar for all the precursors with a slight increase in $\mathrm{H}_{2}$ for higher Na content.

After decomposition at $550^{\circ} \mathrm{C}$ the gas from the reactor was removed and the sample was further heated up to $900^{\circ} \mathrm{C}$. A very 


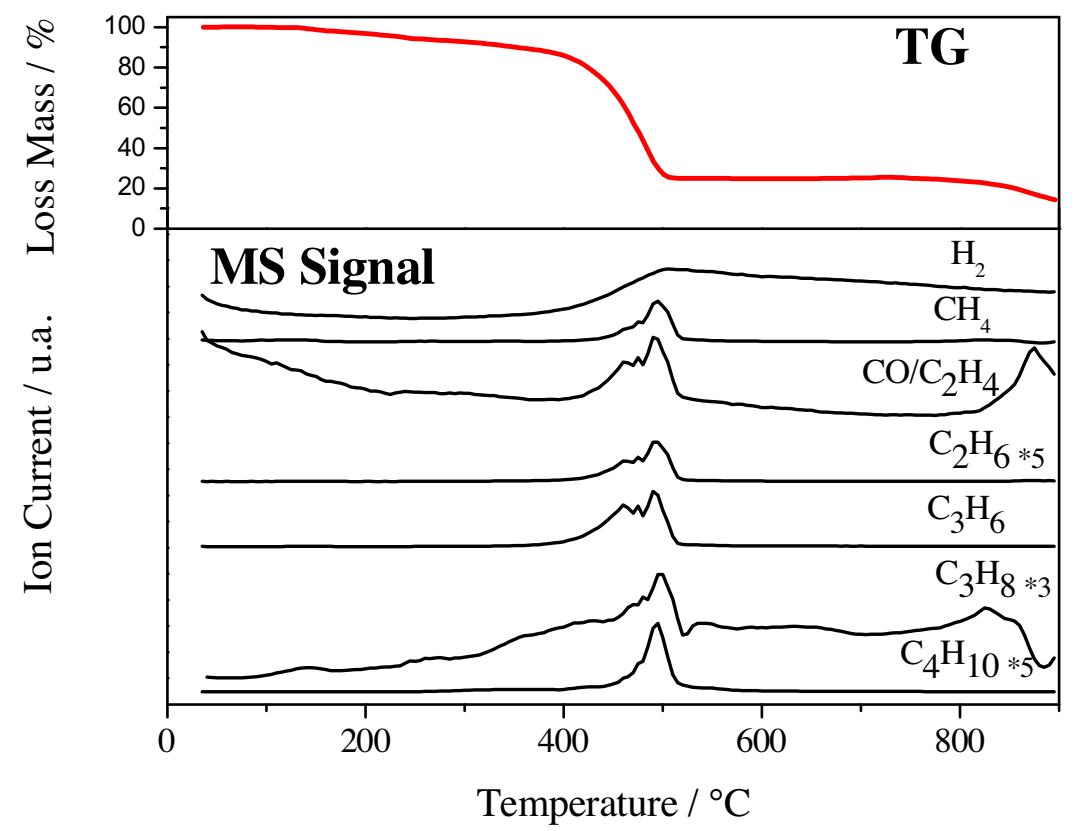

Fig. 9. TG-MS spectrum of the precursor 1.0Na.

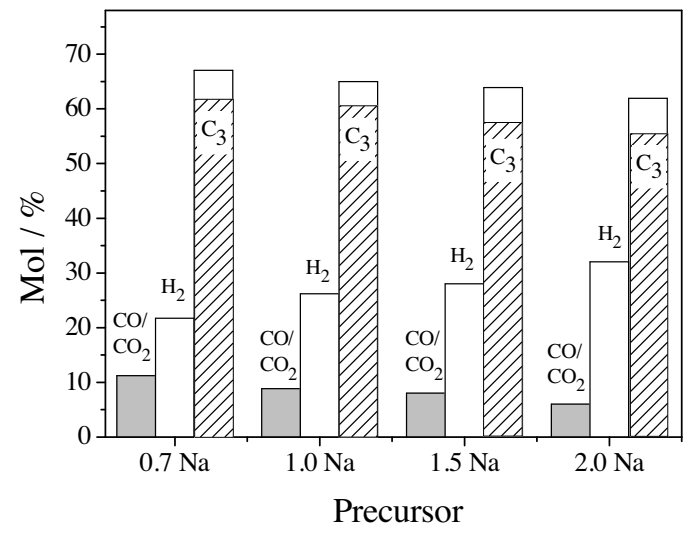

Fig. 10. Gas fraction composition (mol\%) at $550^{\circ} \mathrm{C}$.

small amount of gas was produced between 550 and $900{ }^{\circ} \mathrm{C}$ which is in agreement with the TG weight loss observed at higher temperatures. GC analysis of this gas showed the presence of hydrogen, hydrocarbons and carbon oxides.

\subsection{General considerations}

Considering the information gathered from the mass balance, GC and TG analyses of the different fractions a general idea of product distribution for the precursor 2.0Na is presented in Fig. 11.

It can be observed that the solid product $c a .31 \mathrm{wt} \%$ is composed mainly of sodium carbonate, sodium oxide and carbon. TG results showed that at temperatures near $800^{\circ} \mathrm{C}$ the sodium carbonate decomposes and oxidizes the carbon to produce $\mathrm{CO}$ and $\mathrm{CO}_{2}$ and a white powder composed of $\mathrm{Na}_{2} \mathrm{O}$. The most important aspect of this decomposition/carbon oxidation is the regeneration of $\mathrm{Na}_{2} \mathrm{O}$ which can be reused for a new reaction with more fatty acid.

The liquid products are formed in relatively small amounts and initial IR, UV and CG-MS analyses suggest the significant presence of aromatic compounds (see Supplementary material). A more detailed characterization of this liquid fraction is necessary to envisage potential applications, e.g. fuel, solvent, etc.

The major gas fraction, $58 \mathrm{wt} \%$, was composed of propane and small amounts of $\mathrm{H}_{2}, \mathrm{C}_{1}, \mathrm{C}_{2}$ and $\mathrm{C}_{4}$. The carbon distribution in the different reaction products is shown in Fig. 12.

It can be clearly observed that almost $70 \%$ of the carbon atoms from the oleate ended up as propane and a significant fraction of the $C$ is present in the liquid products.

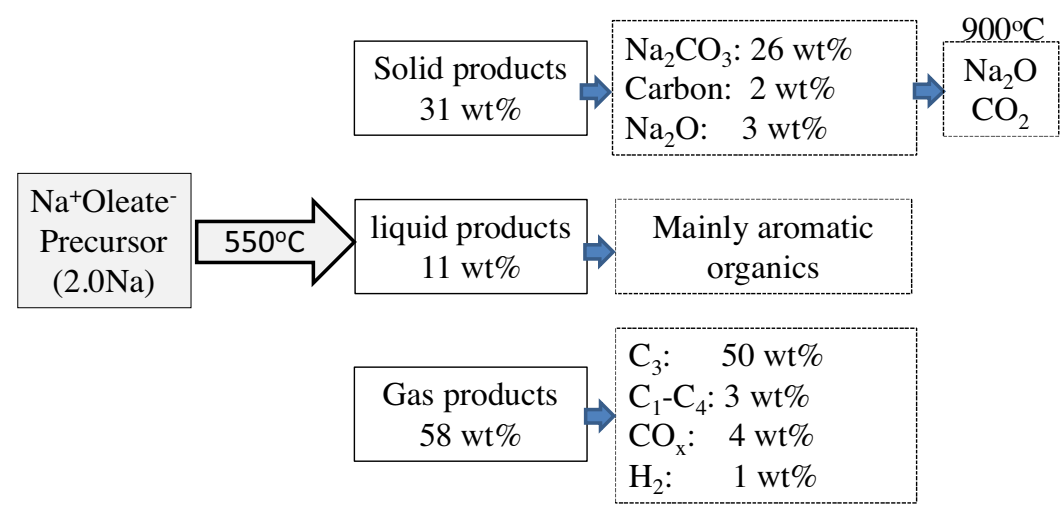

Fig. 11. Product distribution for the 2.0 Na precursor. 


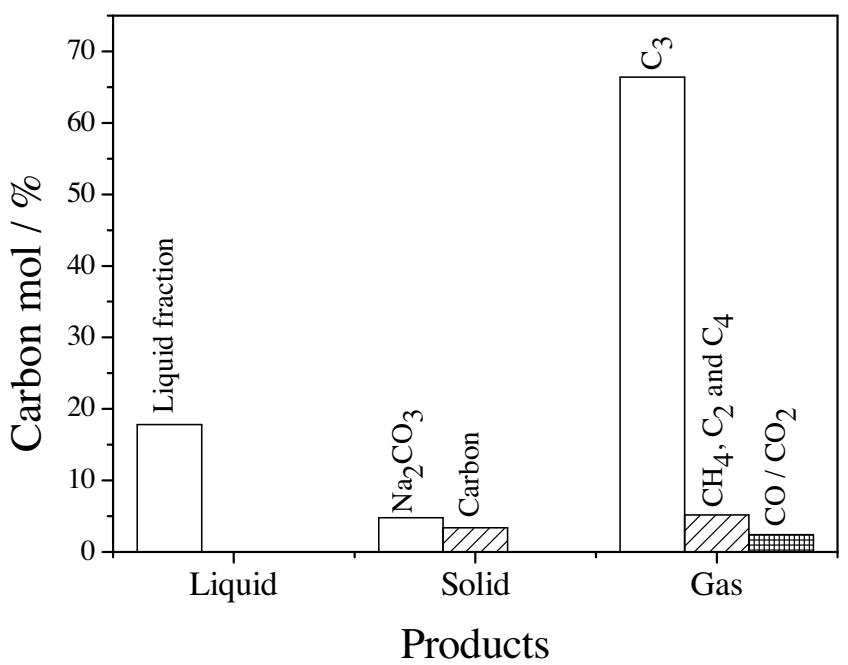

Fig. 12. Carbon atoms distribution (mol\%) in the different products of $2.0 \mathrm{Na}$ decomposition at $550^{\circ} \mathrm{C}$.

Although the reaction mechanism is not clear, apparently a complex reaction involving different processes is taking place during the decomposition of the sodium oleate precursor. Fig. 13 shows some possible reactions.

The hydrocarbon chain is fragmenting to produce propane as the main product. A simple calculation shows that from the $18 \mathrm{C}$ atoms, $12 \mathrm{C}$ will result in 4 propane molecules. The formation of high amounts of propane from $\mathrm{C} 17 \mathrm{H} 33$ chain involves a significant hydrogen transfer among the carbons. As a result of this process, part of the carbons will be converted to aromatic compounds (as observed in the liquid fraction with a $\mathrm{C} / \mathrm{H}$ ratio near $1 / 1$ ) and a significant amount of solid carbon (char). Therefore, these data suggests that the sodium oleate precursor decomposes/cracks, produces/transfers hydrogen and aromatize to small molecules and solid carbon

It is interesting to observe that sodium has a fundamental role in these reactions, since pure oleic acid does not decomposes and only evaporates. The strong basic character of $\mathrm{Na}_{2} \mathrm{O}$ formed in the reaction likely promotes catalytic cracking reactions and also the $\mathrm{H}$ transfer processes [31].

The reason for the remarkable selectivity observed for propane is not clear and further investigation is necessary in order to



Fig. 14. Formation and decomposition cycle of sodium oleate.

understand the possible reaction steps, the interaction of the alkyl chain with the $\mathrm{Na}+$ ion, the dehydrogenation and H-transfer processes.

The obtained results also point to a possible cyclic process where the sodium hydroxide or oxide can be regenerated and reused for a new reaction (Fig. 14 ).

\section{Conclusions}

This work shows that free fatty acid, a common and undesirable contamination present in vegetable oils, can be converted to hydrocarbons by a simple process of reaction with $\mathrm{NaOH}$ followed by a controlled thermal decomposition. In this decomposition process the sodium oleate is converted with a remarkable selectivity to propane and in small amounts $\mathrm{C}_{1}, \mathrm{C}_{2}, \mathrm{C}_{4}$ and $\mathrm{H}_{2}$, which is similar in several aspects to liquefied petroleum gas. This process also results in a liquid mixture with aromatic compounds with potential for use as fuels. The sodium oxide can be regenerated at temperatures higher than $800^{\circ} \mathrm{C}$ and reused for a new reaction cycle.

\section{Acknowledgements}

The authors acknowledge financial support from CNPq, CAPES and FAPEMIG. The authors also would like to acknowledge the Center of Microscopy at UFMG.

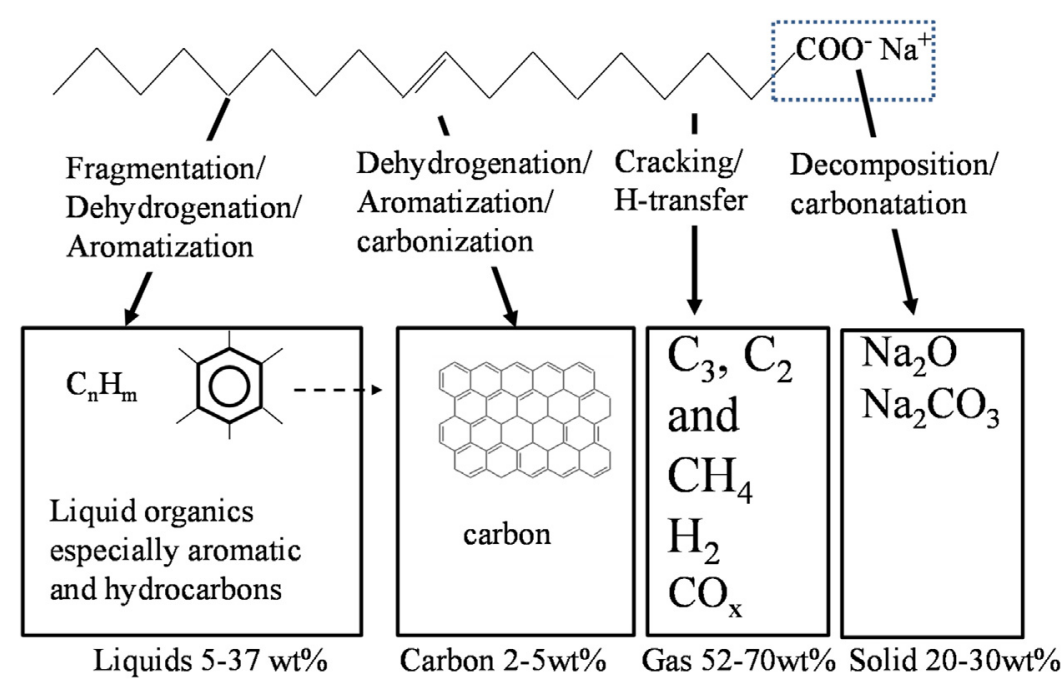

Fig. 13. Scheme of the products formed (wt\%) during the thermal decomposition of the precursor $2.0 \mathrm{Na}$ and the selectivity achieved (mol\%). 


\section{Appendix A. Supplementary data}

Supplementary data associated with this article can be found, in the online version, at http://dx.doi.org/10.1016/j.cattod.2016.04. 035.

\section{References}

[1] S.A. Hosseini, A. Niaei, D. Salari, M.C. Alvarez-Galvan, J.L.G. Fierro, Ceram. Int. 40 (2014) 6157-6163.

[2] P. Hernández-Hipólito, N. Juárez-Flores, E. Martínez-Klimova, A. Gómez-Cortés, X. Bokhimi, L. Escobar-Alarcón, et al., Catal. Today 250 (2015) 187-196.

[3] M. Manríquez-Ramírez, R. Gómez, J.G. Hernández-Cortez, A. Zúñiga-Moreno, C.M. Reza-San Germán, S.O. Flores-Valle, Catal. Today 212 (2013) 23-30.

[4] A. Guldhe, P. Singh, S. Kumari, I. Rawat, K. Permaul, F. Bux, Renew. Energy 85 (2016) 1002-1010.

[5] A.P.C. Teixeira, E.M. Santos, A.F.P. Vieira, R.M. Lago, Chem. Eng. J. 232 (2013) $104-110$.

[6] E.M. Santos, A.P.D.C. Teixeira, F.G. da Silva, T.E. Cibaka, M.H. Araujo, W.X.C. Oliveira, et al., Fuel 150 (2015) 408-414.

[7] C. Vieira Grossi, E. de Oliveira Jardim, M.H. de Araújo, R.M. Lago, M.J. da Silva, Fuel 89 (2010) 257-259.

[8] V.V. Kuss, A.V. Kuss, R.G. Da Rosa, D.a.G. Aranda, Y.R. Cruz, Renew. Sustain. Energy Rev. 50 (2015) 1013-1020.

[9] L.N. Silva, C.C. Cardoso, V.M.D. Pasa, Fuel 166 (2016) 453-460.

[10] H.V. Lee, J.C. Juan, Y.H. Taufiq-Yap, Renew. Energy 74 (2015) 124-132.

[11] L. Wang, X. Dong, H. Jiang, G. Li, M. Zhang, Bioresour. Technol. 158 (2014) 392-395.
[12] M.K. Lam, K.T. Lee, A.R. Mohamed, Biotechnol. Adv. 28 (2010) 500-518.

[13] J.M. Encinar, N. Sánchez, G. Martínez, L. García, Bioresour. Technol. 102 (2011) 10907-10914.

[14] R. Cardeña, G. Moreno, I. Valdez-Vazquez, G. Buitrón, Int. J. Hydrogen Energy (2015) 1-12.

[15] K. Hengst, M. Arend, R. Pfützenreuter, W.F. Hoelderich, Appl. Catal. B Environ. 174-175 (2015) 383-394.

[16] Y. Yang, Q. Wang, X. Zhang, L. Wang, G. Li, Fuel Process. Technol. 116 (2013) $165-174$.

[17] H. Lappi, R. Alén, J. Anal. Appl. Pyrolysis 91 (2011) 154-158.

[18] H.E. Lappi, R.J. Alén, BioResources 6 (2011) 5121-5138 comesources.com.

[19] A. Demirbas, Energy Convers. Manag. 44 (2003) 2093-2109.

[20] C.-C. Chang, S.-W. Wan, Ind. Eng. Chem. 39 (1947) 1543-1548.

[21] F. Yu, Y. Wang, L. Zhang, G. Zhu, Miner. Eng. 71 (2015) 7-12.

[22] J.-W. Kim, H.-G. Lee, Metall. Mater. Trans. B 32 (2001) 17-24.

[23] S. Gunasekaran, G. Anbalagan, S. Pandi, J. Raman Spectrosc. 37 (2006) 892-899.

[24] M.S. Dresselhaus, G. Dresselhaus, R. Saito, A. Jorio, Phys. Rep. 409 (2005) 47-99.

[25] A. Ferrari, J. Robertson, Phys. Rev. B 61 (2000) 14095-14107.

[26] B. Holt, R. Lam, F.C. Meldrum, S.D. Stoyanov, V.N. Paunov, Soft Matter. 3 (2007) 188-190.

[27] J. Jiang, M.-R. Gao, Y.-H. Qiu, G.-S. Wang, L. Liu, G.-B. Cai, et al., CrystEngComm 13 (2011) 952

[28] M. Wang, H.K. Zou, L. Shao, J.F. Chen, Powder Technol. 142 (2004) 166-174.

[29] J.P.C. Trigueiro, G.G. Silva, R.L. Lavall, C.a. Furtado, S. Oliveira, a. S. Ferlauto, et al., J. Nanosci. Nanotechnol. 7 (2007) 3477-3486.

[30] L.C. de A. Barbosa, Espectroscopia no Infravermelho na caracterização de compostos orgânicos. 1st ed., Viçosa, 2007.

[31] L. Li, K. Quan, J. Xu, F. Liu, S. Liu, S. Yu, et al., J. Anal. Appl. Pyrolysis 110 (2014) 313-317. 